\title{
Inequalities in financial risk protection in Bangladesh: an assessment of universal health coverage
}

Md. Rashedul Islam ${ }^{1}$ Md. Shafiur Rahman², Zobida Islam³ , Cherri Zhang B. Nurs², Papia Sultana ${ }^{4}$ and Md. Mizanur Rahman ${ }^{2,5^{*}}$ (D)

\begin{abstract}
Background: Financial risk protection and equity are major components of universal health coverage (UHC), which is defined as ensuring access to health services for all citizens without any undue financial burden. We investigated progress towards UHC financial risk indicators and assessed variability of inequalities in financial risk protection indicators by wealth quintile. We further examined the determinants of different financial hardship indicators related to healthcare costs.
\end{abstract}

Methods: A cross-sectional, three-stage probability survey was conducted in Bangladesh, which collected information from 1600 households from August to November 2011. Catastrophic health payments, impoverishment, and distress financing (borrowing or selling assets) were treated as financial hardship indicators in UHC. Poisson regression models were used to identify the determinants of catastrophic payment, impoverishment and distress financing separately. Slope, relative and concentration indices of inequalities were used to assess wealth-based inequalities in financial hardship indicators.

Results: The study found that around 9\% of households incurred catastrophic payments, 7\% faced distress financing, and $6 \%$ experienced impoverishing health payments in Bangladesh. Slope index of inequality indicated that the incidence of catastrophic health payment and distress financing among the richest households were 12 and 9 percentage points lower than the poorest households respectively. Multivariable Poisson regression models revealed that all UHC financial hardship indicators were significantly higher among household that had members who received inpatient care or were in the poorest quintile. The presence of a member with chronic illness in a household increased the risk of impoverishment by nearly double.

Conclusion: This study identified a greater inequality in UHC financial hardship indicators. Rich households in Bangladesh were facing disproportionately less financial hardship than the poor ones. Households can be protected from financial hardship associated with healthcare costs by implementing risk pooling mechanism, increasing GDP spending on health, and properly monitoring subsidized programs in public health facilities.

Keywords: OOP payment, Catastrophic expenditure, Impoverishment, Hardship financing, Universal health coverage, Inequalities, Bangladesh

\footnotetext{
* Correspondence: mizanur_rub@yahoo.com

${ }^{2}$ Department of Global Health Policy, The University of Tokyo, Tokyo, Japan

${ }^{5}$ Department of Population Science and Human Resource Development,

University of Rajshahi, Rajshahi 6205, Bangladesh

Full list of author information is available at the end of the article
} 


\section{Background}

Achieving universal health coverage (UHC) is one of the key targets in the proposed Sustainable Development Goals (SDGs) [1]. There are two key targets in UHC plan: having at least $80 \%$ essential health service coverage, and $100 \%$ financial risk protection from catastrophic and impoverishing payment for health services by 2030 $[2,3]$. The World Health Organization (WHO) and World Bank (WB) jointly developed a framework for assessing UHC through three dimensions: population, health service coverage, and proportion of health expenditure covered by formal risk pooling mechanisms [2]. Financial risk protection plan is now accepted as a key mechanism to ensure affordable and equitable access to care for all citizens of a country irrespective of their socio-economic statuses [4]. Many countries adopted $\mathrm{UHC}$ as a top priority for their national health systems in order to alleviate poverty and improve health outcomes through ensuring equity in access to care [2].

Similar to other South Asian countries, Bangladesh is simultaneously experiencing a double burden of diseases, low health service coverage, and a lack of financial risk protection mechanism in their health system $[5,6]$. Bangladesh has a dual healthcare systems, with both public and private health services co-existing in most areas. There are three main levels: primary health care, district, and divisional or tertiary levels [7]. The public sector is largely used for outpatient, inpatient, and preventive care, while the private sector is used mainly for outpatient and inpatient curative care. The main public health provider is the Ministry of Health and Family Welfare (MOHFW), which provides primary, secondary and tertiary care through various types of health facilities (such as general hospitals, district hospitals and health clinics). Public health services are heavily subsidized by the government, and primary care services at health clinics are delivered at almost free of charge, with each patient being charged a nominal fee of Bangladesh Taka13 (equivalent to US\$ 0.17 in 2011) for each outpatient visit [8]. Secondary and tertiary care services provided at hospital facilities are also highly subsidized by the government. Private health providers, complementing the medical services provided by the government, mainly focuses on curative services including general practitioner clinics, medical centers, and private hospitals. Bangladesh currently has neither a national health insurance scheme nor a well-developed private insurance market [9]. There are a number of small scale NGO-based community insurance schemes, often operating in conjunction with micro-financing schemes, but these cover less than $1 \%$ of the total population and target mainly poor populations [9].

Health financing is underfunded in Bangladesh; government spend less than one percent of gross domestic product (GDP) on health which is the lowest among South Asian countries [10].

Health sector is also neglected in terms of country's total budget, only $4.3 \%$ of the total budget were allocated for the health sector in financial year 2015-16 [11]. Out-of-pocket (OOP) payment remain the main source of healthcare funding in Bangladesh, making up $63.3 \%$ of total healthcare expenditure [9]. Inequality is another concern in countries with fragile health systems like Bangladesh, and disadvantaged populations are often restricted in their financial access to healthcare services. Inadequate public funding for health services, limited access to health insurance plans, and unexpected OOP payments can trigger asset depletion, indebtedness, and reductions in essential consumption, which in turn prevent access to health services and may ultimately lead to financial catastrophe, distress financing, and impoverishment [12-19].

In order to measure and track Bangladesh's progress towards UHC and its financial risk protection indicators, we assessed incidence of catastrophic and impoverishing health expenditure and distress financing associated with OOP payments. We further examined the determinants of different financial hardship indicators related to healthcare costs using representative survey data.

\section{Methods \\ Study area and design}

This study took place in Rajshahi city of Bangladesh, the third largest city located in the north-western part of the country. Rajshahi district has a population of 2.6 million, with an average household size of approximately four people [20], and broadly represent many urban areas in Bangladesh based on demographic distribution [20]. The literacy rate is 71 and $62 \%$ for males and females, respectively. This was a crosssectional study based on a three-stage, cluster-sampling methodology, which collected information from 1600 households from August to November 2011. The overall response rate was $99.6 \%$.

\section{Data collection}

Interviewers recorded information on household member's socio-demographic characteristics, and household consumption or expenditure in the past 30 days or past 12 months using a structured questionnaire from household heads after obtaining informed consent. The study used a recall period for all illnesses in the past 30 days and at least 3 months' duration for chronic diseases in the year prior to interview. A condition was considered chronic if it lasted or was expected to last for more than 3 months [21]. Data were collected on the onset or duration of illness, diagnosis, treatment response, and cost 
and coping strategies separately. Respondents were asked about their main symptoms and (eventual) diagnoses followed by whether the diagnosis was made by professional medical doctors, i.e. MBBS doctors.

\section{Measurement of outcomes}

In line with other studies, financial risk protection coverage was assessed from incidence of catastrophic and impoverishing health payments [22]. Additionally, incidence of distress financing resulting from OOP was estimated to understand the coping strategy. A household's expenditure was treated as catastrophic if it exceeded $40 \%$ of household capacity to pay [23, 24]. Household capacity to pay refers to the effective income remaining after meeting basic needs that is non-subsistence spending. Subsistence expenditure for each household was estimated by multiplying poverty line with the equivalent household size. A household's health expenditure was treated as impoverishing when its total per capita consumption spending fell below the poverty line after paying for health care. We estimated the poverty line based on subsistence food expenditure as proposed by World Health Organization [24, 25]. The poverty line was determined based on the average food consumption at the 45th and 55th percentiles of the total household expenditure of the sampled household. Household consumption expenditure was estimated following the standard guidelines [26]. Distress financing involves funding for healthcare costs by borrowing money from relatives or bank and selling household assets [16, 27].

\section{Covariates}

In this study, the average number of children and adults per household, presence of household member aged over 65 years, presence of chronic illness in any member of the household, care-seeking behavior, household consumption quintile, household size, and household head educational status were considered as covariates.

\section{Statistical analysis}

Descriptive statistics were calculated using the mean (confidence interval) or frequency and proportions as appropriate. Poisson regression was used to identify the determinants of catastrophic health expenditure, impoverishment, and distress financing. For equity analysis, socio-economic status of each household was assessed based on household total consumption expenditure. Households were ranked in ascending order based on per capita total consumption expenditure, and divided into quintiles, with quintile 1 (Q1) as the poorest $20 \%$ of households and quintile 5 (Q5) representing the richest. We assessed both absolute and relative measures of equity. The slope index of inequality [SII] was used as an absolute measure of inequality, whereas the relative index of inequality [RII] and the concentration index were used as relative measures of inequality [28]. The main purpose of absolute index of inequalities is to interpret the difference in coverage between the extreme wealth quintiles (Q5-Q1). The SII reflects the difference in coverage values in percentage points between individuals at the top and bottom of the wealth scales. We calculated the SII and RII by regressing financial hardship indicators against the household's relative rank in the cumulative distribution of wealth position. The concentration index indicates the magnitude of relative inequality [28-30]. This index produced values that ranged from -1 to 1 . When the concentration index value is zero there is no inequality i.e. no difference in financial burden between poor and rich populations. A negative value indicates the poor population is incurring more financial burden, while a positive value indicates the rich population is facing more financial burden. All analyses were adjusted for the probability sample design. Data management and analysis was performed in Stata/MP Version 14.0.

\section{Results \\ Background characteristics}

The average household size in the sample of Rajshahi city was 4.6 (95\% CI: 4.5-4.7) and the average number of dependent members was 2.0 (95\% CI: 2.0-2.1) per household (Additional file 1: Table S1). The average number of illnesses was 2.8 per household (95\% CI: 2.6-2.9). About 71.5\% (95\% CI: 67.4-75.2) of households had at least one chronic illness in the past 12 months prior to interview. Of the 1593 completed households, 92\% incurred health expenditure in the past 30 days recall period. The sociodemographic characteristics of our study population are presented in Table 1.

\section{Equity in financial hardship indicators}

Around 9.0\% (95\% CI: 7.2-11.2) of households incurred catastrophic health payment, 5.6\% (95\% CI: 4.5-7.0) of households experienced impoverishing health expenditure, and $7.0 \%$ (95\% CI: 5.3-9.2) faced distress financing to pay for health care costs (Fig. 1). Detailed proportion of financial hardship by different socio-demographic characteristics is presented in the Additional file 1 (Table S2). Concentration curves for catastrophic payment and distress financing both lie above the line of equality, indicating a disproportionately higher concentration of catastrophic payment and distress financing in poor households than in rich ones (Fig. 2). Significant differences in catastrophic payment and distress financing among poor and rich households were found in all three measures of inequality indices (Table 2). The SII indicated that incidence of catastrophic health payment and distress financing among the richest households were 12 and 9 percentage points lower than poorest households respectively (Table 2 ). 
Table 1 Descriptive statistics of households and household heads, Bangladesh, 2011

\begin{tabular}{llll}
\hline Household characteristics & Frequency & Percentage & $95 \% \mathrm{Cl}$ \\
\hline Gender of household head & & & \\
Male & 1447 & 90.5 & $88.6-92.1$ \\
Female & 146 & 9.5 & $7.9-11.4$
\end{tabular}

Educational status of household head

$\begin{array}{llll}\text { No education } & 258 & 17.1 & 13.9-20.8 \\ \text { Primary } & 310 & 20.8 & 17.4-24.7 \\ \text { Secondary } & 420 & 27.2 & 24.5-30.2 \\ \text { Higher } & 605 & 34.9 & 29.2-41.1 \\ \text { Household member over 65 years } & & & \\ \text { Yes } & 136 & 8.5 & 7.0-10.2 \\ \text { No } & 1457 & 91.6 & 89.8-93.1\end{array}$

Presence of illness in the last 30 days

$\begin{array}{llll}\text { Yes } & 1501 & 93.7 & 91.4-95.3 \\ \text { No } & 92 & 6.3 & 4.8-8.3\end{array}$

Member with chronic disease

$\begin{array}{llll}\text { Yes } & 1148 & 71.5 & 67.4-75.2 \\ \text { No } & 445 & 28.5 & 24.8-32.6\end{array}$

Utilization of health services

\begin{tabular}{llll} 
Inpatient & 65 & 4.3 & $3.21-5.6$ \\
Outpatient public & 253 & 16.1 & $13.6-18.9$ \\
Outpatient private & 385 & 22.8 & $19.7-26.2$ \\
Outpatient public and private & 105 & 6.3 & $4.7-8.4$ \\
Self-medication/traditional healer & 785 & 50.6 & $45.8-55.3$ \\
\hline
\end{tabular}

Cl confidence interval

\section{Determinants of financial hardship}

Table 3 presents the results from the Poisson regression model of risk factors for catastrophic health payment, impoverishment, and distress financing. Household consumption quintile was inversely associated with all three

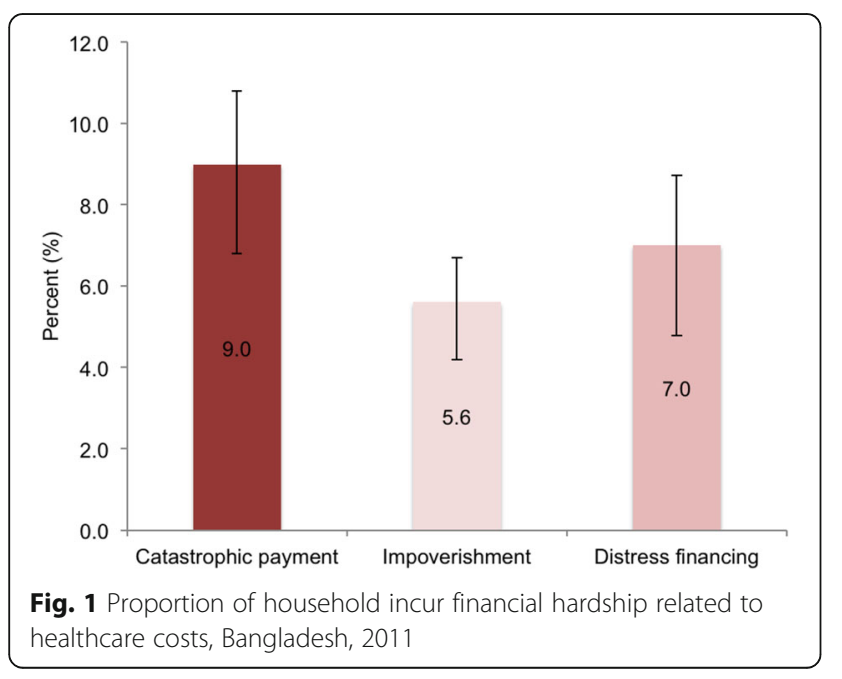

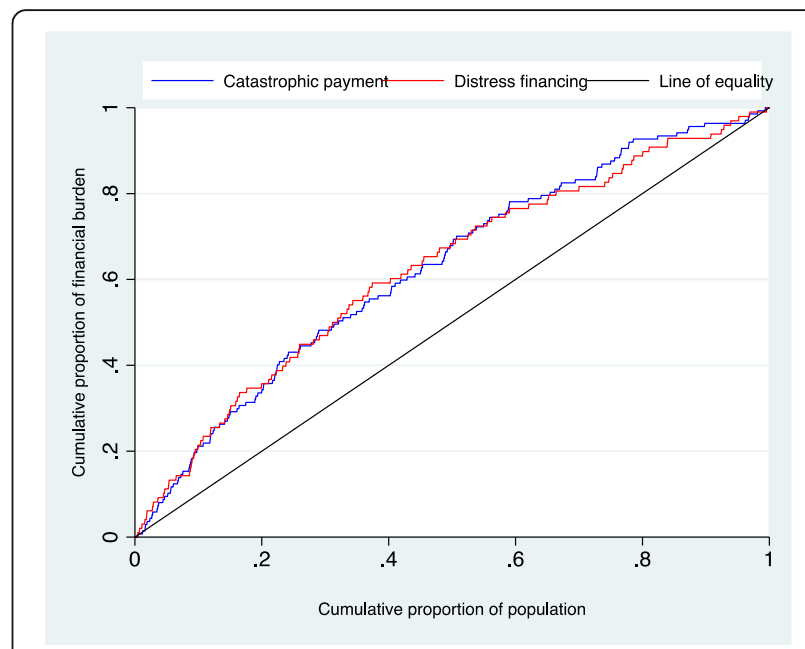

Fig. 2 Concentration curve for catastrophic payment and distress financing related to health care costs, Bangladesh, 2011

financial hardship indicators. Households in the poorest quintile were more likely to incur catastrophic payment, impoverishment and distress financing than the richest quintile. Utilization of health services was also significantly associated with three financial hardship indicators, with those using inpatient care services having the largest relative risk. The presence of a member with chronic illness in a household increased the risk of impoverishment by a factor of 1.9 (95\% CI: 1.1-3.4).

\section{Discussion}

This study found residents in Bangladesh faced serious problems with healthcare financing. This is the first study in Bangladesh to include evidence in health financing research regarding inequalities in UHC financial risk protection indicators. From this study, we found that around one in ten household incurred financial catastrophe, and one in 20 non-poor households became poor due to healthcare costs. Poor households spent less

Table 2 Inequalities in catastrophic payment and distress financing related to health care costs, Bangladesh, 2011

\begin{tabular}{lll}
\hline & Catastrophic payments & Distress financing \\
\hline Household consumption quintile, \% $(95 \% \mathrm{Cl})$ & \\
Quintile 1 (poorest) & $14.3(10.3-19.6)$ & $11.7(8.3-16.4)$ \\
Quintile 2 & $9.7(6.2-15.0)$ & $7.6(4.9-11.7)$ \\
Quintile 3 & $9.2(5.7-14.5)$ & $6.1(3.1-11.8)$ \\
Quintile 4 & $7.1(4.3-11.4)$ & $4.8(2.6-8.6)$ \\
Quintile 5 (richest) & $3.4(1.7-6.4)$ & $3.9(2.0-7.7)$ \\
Inequality index, (95\% Cl) & & \\
Slope index of inequality (Q5-Q1) & $-12.0(-18.6$ to -5.4$)$ & $-9.3(-15.0$ to -3.5$)$ \\
Relative index of inequality (Q5:Q1) & $0.3(0.1-0.5)$ & $0.3(0.1-0.5)$ \\
Concentration index & $-0.2(-0.3$ to -0.1$)$ & $-0.2(-0.3$ to -0.1$)$ \\
\hline
\end{tabular}

Cl Confidence interval 
Table 3 Multiple Poisson regression model for financial hardship indicators, Bangladesh, 2011

\begin{tabular}{|c|c|c|c|}
\hline \multirow[t]{2}{*}{ Variable } & \multicolumn{3}{|c|}{ Relative risk (95\% confidence interval) } \\
\hline & Catastrophic payment & Impoverishment & Borrowing or selling \\
\hline Average number of children in $\mathrm{HH}$ & $1.12(1.02-1.23)$ & $1.04(0.9-1.19)$ & $1.01(0.89-1.14)$ \\
\hline Average number of adult in $\mathrm{HH}$ & $1.39(1.03-1.87)$ & $1.25(0.92-1.69)$ & $1.38(1.03-1.85)$ \\
\hline \multicolumn{4}{|l|}{ Member with chronic disease } \\
\hline Yes & $1.41(0.87-2.29)$ & $1.90(1.08-3.36)$ & $1.70(0.87-3.31)$ \\
\hline No & 1.00 & 1.00 & 1.00 \\
\hline \multicolumn{4}{|l|}{ HH member over 65 years } \\
\hline Yes & $1.22(0.79-1.90)$ & $1.11(0.53-2.34)$ & $1.50(0.81-2.79)$ \\
\hline No & 1.00 & 1.00 & 1.00 \\
\hline \multicolumn{4}{|l|}{$\mathrm{HH}$ consumption quintile } \\
\hline Quintile 1 (poorest) & $4.26(1.67-10.88)$ & $17.34(3.73-80.55)$ & $4.03(1.72-9.45)$ \\
\hline Quintile 2 & $2.84(1.15-7.05)$ & $5.19(1.14-23.71)$ & $2.23(0.91-5.45)$ \\
\hline Quintile 3 & $2.65(1.25-5.59)$ & $3.11(0.92-10.49)$ & $1.57(0.64-3.83)$ \\
\hline Quintile 4 & $2.28(1.12-4.65)$ & $2.71(0.98-7.52)$ & $1.39(0.62-3.12)$ \\
\hline Quintile 5 (richest) & 1.00 & 1.00 & 1.00 \\
\hline Household size & $0.98(0.88-1.09)$ & $1.03(0.89-1.19)$ & $1.07(0.95-1.21)$ \\
\hline \multicolumn{4}{|l|}{ Care-seeking behavior } \\
\hline Inpatient & $6.67(4.50-9.90)$ & $7.09(3.68-13.65)$ & $3.95(2.52-6.18)$ \\
\hline Outpatient public & $0.67(0.40-1.13)$ & $0.99(0.51-1.9)$ & $0.60(0.32-1.11)$ \\
\hline Outpatient private & 1.00 & 1.00 & 1.00 \\
\hline Outpatient public and private & $1.58(0.93-2.68)$ & $1.35(0.63-2.9)$ & $1.59(0.78-3.23)$ \\
\hline Self-medication/traditional healer & $0.24(0.13-0.44)$ & $0.35(0.17-0.69)$ & $0.23(0.12-0.44)$ \\
\hline \multicolumn{4}{|l|}{ Household head education } \\
\hline No education & $2.46(1.34-4.53)$ & $1.40(0.57-3.45)$ & $1.60(0.72-3.53)$ \\
\hline Primary & $1.71(0.92-3.17)$ & $1.14(0.48-2.7)$ & $1.78(0.83-3.82)$ \\
\hline Secondary & $1.39(0.81-2.39)$ & $0.61(0.25-1.47)$ & $1.29(0.62-2.66)$ \\
\hline Higher & 1.00 & 1.00 & 1.00 \\
\hline
\end{tabular}

$H H$ household

on healthcare, facing disproportionately higher financial burden.

On average, households spent about $11.0 \%$ of their total household budget on healthcare, and had high incidence of financial hardship as a result of OOP healthcare payments. The study demonstrated that the overall rate of impoverishment was 5.6\%. Similar rates of impoverishment was found in China (5.7\%) and Vietnam (7.7\%) [31]. Our study also found that around $7 \%$ of households faced distress financing (borrowing or selling household assets) to pay for healthcare costs. Consistent with other studies in developing nations [19, 27, 32], the risk of using distress financing was strongly associated with household socio-economic status. Financial hardship including catastrophic payment and distress financing from healthcare were substantially high in the poorest households compared to their richest counterparts, and this is consistent with previous studies from developing countries [31, 33, 34].

Financial hardship is closely linked with the utilization of health services in Bangladesh. In this study, incidence of financial hardship for inpatient care was quite different from those that received care in outpatient facilities. For example, inpatient treatment costs incurred around $69 \%$ of financial catastrophe, $41 \%$ of impoverishment, and $37 \%$ of distress financing, while the proportion was nearly four times lower among public and private outpatient care. These findings were similar to several studies from developing countries [19, 27]. According to $\mathrm{Xu}$ and colleagues [25], the availability of health services requiring OOP payments, low ability to pay, and absence of health insurance are the three key preconditions for financial risk including catastrophic payments, impoverishment, or distress financing. We found that all these 
conditions were present in our study area. Therefore, it is clear that public health services fail to perform their social safety net roles properly.

The higher burden of financial hardship found in this study proved that health financing in Bangladesh relies heavily on OOP payments for both public and private health services. A previous study suggested that although about $70 \%$ of households in Bangladesh received inpatient treatment from public facilities, but were more likely to receive outpatient treatment in private health services [35]. Subsidized public health services in Bangladesh may be associated with financial risk because of unofficial charges, tips, lack of monitoring systems in subsidized programs, and dependency on private health markets for essential ancillary services such as medical supplies and drugs [35]. For instance, a study in Bangladesh reported that the average level of per-patient unofficial fees was 12 times the amount that could be expected in official payments - assuming that no respondents were exempted from paying official fees [36].

In Bangladesh, although health has been prioritized since the inception of the First Five Year Plan (1973-1978), for the first four decades after independence, the country lacked a national health financing policy to reduce the burden of financial hardship caused by OOP health payment. Bangladesh's first 20 years health care financing strategy, developed in 2012, had a vision to halve the share of OOP payment in total health expenditure and to implement a social health protection scheme by 2032 through raising tax revenue and mandatory social health contribution [37]. However, the implementation of social protection scheme remained a challenge since majority of the people are engaged in informal sectors. The government of Bangladesh aims to increase the allocation of budget for health to $15 \%$ by 2032 from its current level of about 5\%, which might be challenging. The government recently implemented a pilot project of health insurance, called Shastyo Suroksha Karmasuchi (SSK), for the population of three sub-districts of Dhaka division living below the poverty line. The benefit package includes one health card for each household and free treatment services for 50 diseases. The per capita health expenditure in Bangladesh has been increasing over the years, from 9.1 US dollars in 2000 to 30.8 US dollars by 2014. The benefit package might be insufficient to protect poor households from the burden of OOP payment considering the ever-increasing health expenditure. The reduction of OOP payment burden will be difficult unless national health insurance scheme is to be implemented to cover all citizens with priority for the poor population. A nationwide implementation of health scheme with better benefit package for total population like Universal Coverage Scheme of Thailand or Seguro Popular of Mexico can protect people from this high burden of OOP payment [38, 39]. Through the introduction of risk pooling mechanisms, many other low-, middle- and high-income countries have successfully reduced user fees at the point of care and mitigated the economic risk that OOP payments posed for families [33, 40].

\section{Strength and limitations}

The research protocol and sampling process in this study was designed carefully to avoid any bias in the results. Despite this, the study has some limitations. First, the study was conducted only in urban populations from one metropolitan area of the country; therefore the results cannot necessarily be generalized to the whole country. However, we selected our study subjects through a random selection process to improve the representative nature of the sample which may be applicable to other urban areas in Bangladesh. Second, our study was cross-sectional, leading to its inability to capture seasonal variations in household consumption or illness-related expenditure and coping strategies. Third, a relatively small number of households experienced inpatient hospitalization in the past 30 days recall period so we were unable to provide any result separately for inpatient public versus inpatient private facilities.

\section{Conclusion}

The study clearly revealed that the existing health financing system in Bangladesh fails to protect households from financial risk associated with health service. Therefore, health financing reform is essential to protect people from financial shocks caused by OOP payment. Reforms should include increasing government spending on health through budget reallocation, proper monitoring of subsidized programs, ensuring standard costs for both official and unofficial fees across all public facilities, and committing to health insurance for the whole population.

\section{Additional file}

Additional file 1: Table S1. Basic characteristics of households, Bangladesh, 2011. Table S2. Incidence of catastrophic expenditure, impoverishment and distress financing by care-seeking behavior and household characteristics, Bangladesh, 2011. (DOC 62 kb)

\section{Abbreviations \\ Cl: Confidence interval; GDP: Gross domestic product; NGO: Non-Governmental Organization; OOP: Out-of-pocket; RII: Relative index of inequality; SDGs: Sustainable development goals; SII: Slope index of inequality; SSK: Shastyo Suroksha Karmasuchi; UHC: Universal health coverage; WB: World Bank; WHO: World Health Organization}

\section{Acknowledgements}

The authors thank the Department of Statistics and Department of Population Science and Human Resource Development, University of Rajshahi, head and other members, project trainers; project coordinators and supervisors for their assistances. The authors also thank the study subjects for their cooperation and participation. 


\section{Funding}

There is no funding for this manuscript.

\section{Availability of data and materials}

The datasets and materials used in this study are available upon request to the corresponding author.

\section{Authors' contributions}

MRI and MMR conceptualized the study design. MRI drafted the paper. MR and MSR performed the statistical analysis together with MMR and ZI. SP supported administrative, technical, and field supervision. MMR and CZ revised it critically for important intellectual content. All authors have reviewed and approved the final manuscript.

\section{Competing interests}

The authors declare that they have no competing interests.

\section{Consent for publication}

Not applicable.

\section{Ethics approval and consent to participate}

This study received ethical approval from the Research Ethics Committee of the Bangladesh National Research Ethics Committee, with reference number BMRC/ NREC/2010-2013/1161. A consent form to obtain verbal or written consent from respondents was proposed and approved by the Ethics Committee together with the study protocol. Prior to the interview, our enumerator carefully read the consent form to the subject and then very briefly explained the aims and importance of the study. This consent form contained information on the objectives of the study, risks, benefits and freedom of participation, and confidentiality.

\section{Publisher's Note}

Springer Nature remains neutral with regard to jurisdictional claims in published maps and institutional affiliations.

\section{Author details}

'Department of Computer Science, Uttara Commerce College, Dhaka, Bangladesh. 'Department of Global Health Policy, The University of Tokyo, Tokyo, Japan. ${ }^{3}$ Department of Public Health, First Capital University of Bangladesh, Chuadanga, Bangladesh. ${ }^{4}$ Department of Statistics, University of Rajshahi, Rajshahi, Bangladesh. ${ }^{5}$ Department of Population Science and Human Resource Development, University of Rajshahi, Rajshahi 6205, Bangladesh.

\section{Received: 25 December 2016 Accepted: 30 March 2017}

\section{Published online: 04 April 2017}

\section{References}

1. UN General Assembly. Transforming our world: the 2030 agenda for Sustainable Development. New York: United Nations; 2015.

2. World Health Organization, World Bank Group. Monitoring progress towards universal health coverage at country and global levels, Framework measures and targets. Geneva: World Health Organization and International Bank for Reconstruction and Development, World Bank; 2014.

3. Boerma T, Eozenou P, Evans D, Evans T, Kieny M-P, Wagstaff A. Monitoring progress towards universal health coverage at country and global levels. PLoS Med. 2014;11:e1001731.

4. World Health Organization. The world health report 2010, Health systems financing: the path to universal coverage. Geneva: World Health Organization; 2010.

5. Saquib N, Saquib J, Ahmed T, Khanam MA, Cullen MR. Cardiovascular diseases and type 2 diabetes in Bangladesh: a systematic review and meta-analysis of studies between 1995 and 2010. BMC Public Health. 2012;12:434.

6. Vos T, Allen C, Arora M, Barber RM, Bhutta ZA, Brown A, Carter A, Casey DC, Charlson FJ, Chen AZ, et al. Global, regional, and national incidence, prevalence, and years lived with disability for 310 diseases and injuries, 1990-2015: a systematic analysis for the Global Burden of Disease Study 2015. Lancet. 2016;388:1545-602.

7. Ministry of Health and Family Welfare. Health Bulletin 2010. Dhaka: Government of the People's Republic of Bangladesh; 2011.
8. Bangladesh Health Watch. Bangladesh health watch 2011 - Moving towards universal health coverage. Dhaka: James P Grant School of Public Health; 2012

9. World Health Organization. World health statistics 2011. Geneva: World Health Organization; 2011.

10. Dieleman JL, Templin T, Sadat N, Reidy P, Chapin A, Foreman K, Haakenstad A, Evans T, Murray CJ, Kurowski C. National spending on health by source for 184 countries between 2013 and 2040. Lancet. 2016;387:2521-35.

11. Hassan MZ, Fahim SM, Zafr AHA, Islam MS, Alam S. Healthcare financing in Bangladesh: challenges and recommendations. Bangladesh J Med Sci. 2016;15:505-10

12. Chuma J, Gilson L, Molyneux C. Treatment-seeking behaviour, cost burdens and coping strategies among rural and urban households in Coastal Kenya: an equity analysis. Trop Med Int Health. 2007;12:673-86.

13. Ezeoke OP, Onwujekwe OE, Uzochukwu BS. Towards universal coverage: examining costs of illness, payment, and coping strategies to different population groups in Southeast Nigeria. Am J Trop Med Hyg. 2012;86:52-7.

14. Huffman MD, Rao KD, Pichon-Riviere A, Zhao D, Harikrishnan S, Ramaiya K, Ajay VS, Goenka S, Calcagno J, Caporale JE, et al. A cross-sectional study of the microeconomic impact of cardiovascular disease hospitalization in four Low- and Middle-Income Countries. PLoS One. 2011;6:e20821.

15. Kabir MA, Rahman A, Salway S, Pryer J. Sickness among the urban poor: a barrier to livelihood security. J Int Dev. 2000;12:707-22.

16. Leive A, Xu K. Coping with out-of-pocket health payments: empirical evidence from 15 African countries. Bull World Health Organ. 2008:86:849-56.

17. Mclntyre D, Thiede M, Dahlgren G, Whitehead M. What are the economic consequences for households of illness and of paying for health care in low-and middle-income country contexts? Soc Sci Med. 2006;62:858-65.

18. Russell S. The economic burden of illness for households in developing countries: a review of studies focusing on malaria, tuberculosis, and human immunodeficiency virus/acquired immunodeficiency syndrome. Am J Trop Med Hyg. 2004;71:147-55.

19. Steinhardt LC, Waters $H$, Rao KD, Naeem AJ, Hansen P, Peters DH. The effect of wealth status on care seeking and health expenditures in Afghanistan. Health Policy Plan. 2009:24:1-17.

20. Bangladesh Bureau of Statistics. Bangladesh population and housing census 2011. Dhaka: Ministry of Planning, Government of the People's Republic of Bangladesh; 2012.

21. Perrin EC, Newacheck P, Pless IB, Drotar D, Gortmaker SL, Leventhal J, Perrin JM, Stein RE, Walker DK, Weitzman M. Issues involved in the definition and classification of chronic health conditions. Pediatrics. 1993;91:787-93.

22. World Health Organization. Tracking universal health coverage: first global monitoring report. Geneva: World Health Organization; 2015.

23. O'Donnell O, Van Doorsslaer E, Wagstaff A, Lindelöw M. Analyzing health equity using household survey data: a guide to techniques and their implementation. Washington DC: The World Bank; 2008.

24. Xu K. Distribution of health payments and catastrophic expenditures methodology. Geneva: World Health Organization; 2005.

25. Xu K, Evans DB, Kawabata K, Zeramdini R, Klavus J, Murray CJ. Household catastrophic health expenditure: a multicountry analysis. Lancet. 2003:362:111-7.

26. Deaton A, Zaidi S. Guidelines for constructing consumption aggregates for welfare analysis. Living standards measurement study. Working paper no. 135. Washington DC: The World Bank; 2002.

27. Nguyen KT, Khuat OT, Ma S, Pham DC, Khuat GT, Ruger JP. Coping with health care expenses among poor households: evidence from a rural commune in Vietnam. Soc Sci Med. 2012;74:724-33.

28. Barros AJ, Victora CG. Measuring coverage in $\mathrm{MNCH}$ : determining and interpreting inequalities in coverage of maternal, newborn, and child health interventions. PLoS Med. 2013;10:e1001390.

29. Kakwani N, Wagstaff A, Van Doorslaer E. Socioeconomic inequalities in health: measurement, computation, and statistical inference. J Econ. 1997;77:87-103.

30. World Health Organization. Handbook on health inequality monitoring with a special focus on low-and middle-income countries. Geneve: World Health Organization; 2013.

31. Reddy SR, Ross-Degnan D, Zaslavsky AM, Soumerai SB, Wagner AK. Health care payments in the Asia Pacific: validation of five survey measures of economic burden. Int J Equity Health. 2013:12:49.

32. Kruk ME, Goldmann E, Galea S. Borrowing and selling to pay for health care in low- and middle-income countries. Health Aff (Millwood). 2009; 28:1056-66.

33. Li Y, Wu Q, Xu L, Legge D, Hao Y, Gao L, Ning N, Wan G. Factors affecting catastrophic health expenditure and impoverishment from medical 
expenses in China: policy implications of universal health insurance. Bull World Health Organ. 2012;90:664-71.

34. Shi W, Chongsuvivatwong V, Geater A, Zhang J, Zhang H, Brombal D. Effect of household and village characteristics on financial catastrophe and impoverishment due to health care spending in Western and Central Rural China: A multilevel analysis. Health Res Policy Syst. 2011;9:16.

35. Saksena P, Xu K, Elovainio R, Perrot J. Utilization and expenditure at public and private facilities in 39 low-income countries. Trop Med Int Health. 2012;17:23-35.

36. Killingsworth JR, Hossain N, Hedrick-Wong Y, Thomas SD, Rahman A, Begum T. Unofficial fees in Bangladesh: price, equity and institutional issues. Health Policy Plan. 1999;14:152-63.

37. Ministry of Health and Family Welfare. Expanding social protection for health: towards universal coverage, Health Care Financing Strategy 2012-2032. Dhaka: Health Economics Unit, Ministry of Health and Family Welfare, Government of the People's Republic of Bangladesh; 2012

38. Tangcharoensathien V, Pitayarangsarit S, Patcharanarumol W, Prakongsai P Sumalee $\mathrm{H}$, Tosanguan J, Mills A. Promoting universal financial protection: how the Thai universal coverage scheme was designed to ensure equity. Health Res Policy Syst. 2013;11:25.

39. Knaul FM, González-Pier E, Gómez-Dantés O, García-Junco D, Arreola-Ornelas H, Barraza-Lloréns M, Sandoval R, Caballero F, Hernández-Avila M, Juan M. The quest for universal health coverage: achieving social protection for all in Mexico. Lancet. 2012;380:1259-79.

40. Lagomarsino G, Garabrant A, Adyas A, Muga R, Otoo N. Moving towards universal health coverage: health insurance reforms in nine developing countries in Africa and Asia. Lancet. 2012;380:933-43.

\section{Submit your next manuscript to BioMed Central and we will help you at every step:}

- We accept pre-submission inquiries

- Our selector tool helps you to find the most relevant journal

- We provide round the clock customer support

- Convenient online submission

- Thorough peer review

- Inclusion in PubMed and all major indexing services

- Maximum visibility for your research

Submit your manuscript at www.biomedcentral.com/submit

) Biomed Central 